\title{
Une histoire de la mémoire judiciaire de l'antiquité à nos jours, Études réunies par Olivier Poncet et Isabelle Storez-Brancourt
}

\section{Andrea Schellino}

\section{(2) OpenEdition \\ 1 Journals}

\section{Edizione digitale}

URL: http://journals.openedition.org/studifrancesi/6145

DOI: $10.4000 /$ studifrancesi.6145

ISSN: 2421-5856

\section{Editore}

Rosenberg \& Sellier

\section{Edizione cartacea}

Data di pubblicazione: 1 mai 2011

Paginazione: 232-233

ISSN: 0039-2944

\section{Notizia bibliografica digitale}

Andrea Schellino, «Une histoire de la mémoire judiciaire de l'antiquité à nos jours, Études réunies par Olivier Poncet et Isabelle Storez-Brancourt», Studi Francesi [Online], 163 (LV | I) | 2011, online dal 30 novembre 2015, consultato il 07 janvier 2021. URL: http://journals.openedition.org/studifrancesi/6145 ; DOI: https://doi.org/ERREUR PDO dans /localdata/www-bin/Core/Core/Db/Db.class.php L.34 : SQLSTATE[HYO00] [2006] MySQL server has gone away

Questo documento è stato generato automaticamente il 7 janvier 2021.

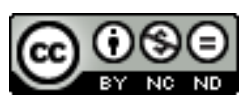

Studi Francesi è distribuita con Licenza Creative Commons Attribuzione - Non commerciale - Non opere derivate 4.0 Internazionale. 


\title{
Une histoire de la mémoire judiciaire de l'antiquité à nos jours, Études réunies par Olivier Poncet et Isabelle Storez- Brancourt
}

\author{
Andrea Schellino
}

\section{NOTIZIA}

AA. VV., Une histoire de la mémoire judiciaire de l'antiquité à nos jours, Études réunies par Olivier PONCET et Isabelle STOREZ BRANCOURT, Paris, École nationale des chartes, 2009, «Études et rencontres de l'école des chartes, 29», pp. 418.

1 Il composito volume presentato da Olivier PONCET e Isabelle STOREZ-BRANCOURT è perlopiù frutto di un colloquio internazionale organizzato dall'Institut d'his-toire du droit (UMR 718, Université Panthéon-Assas-Paris II-CNRS-Archives nationales) e dall'École nationale des chartes, tenutosi a Parigi dal 12 al 14 marzo 2008; esso raccoglie interventi interdisciplinari di storici del diritto, giuristi e archivisti, che abbracciano la cultura giuridica occidentale dall'Antichità ai nostri giorni.

2 Il fulcro di questa impresa d'ampio respiro è il concetto di "memoria giudiziaria", la cui analisi storiografica non ricopre l'intero campo degli studi storici di carattere giudiziario. Come chiarito da Storez-Brancourt nell'Introduction, occorre distinguere a titolo generale tre elementi nella memoria: il processo, il contenuto e la conservazione. La memoria è la funzione psicologica che permette al soggetto di conservare e ricordare una conoscenza, le tracce di un sapere o un'esperienza; il funzionamento della memoria individuale interferisce evidentemente nella costruzione della storia, e di quella giuridica in particolare: «les acteurs de la justice (juges, auxiliares de justice, parties, public), dotés de cette faculté, ont exprimé parfois, à titre privé ou public, se souvenir d'événements judiciaires auxquels ils s'étaient trouvé mêlés» (p.6). 
Naturalmente, nella trasmissione del fatto giudiziario, lo scritto ha una parte fondamentale; lo storico incontra pertanto nei testi le basi della memoria giudiziaria, le regole ed i meccanismi che conducono alla moderna archivistica giudiziaria. Accanto a questi scritti si profilano inoltre gli specialisti del mestiere: scribi, notarii, cancellieri...

3 Gli articoli raccolti nel presente volume sono quindi prevalentemente incentrati su questi processi della memoria collettiva, con una particolare attenzione per la questione della conservazione e della perpetuazione delle decisioni di giustizia e per $\mathrm{i}$ suoi protagonisti; si è scelto quindi di escludere le memorie del diritto e delle leggi, nonché la giurisprudenza.

4 I tre assi naturali della presente ricerca sono dunque l'«archeologia» della memoria giudiziaria, ossia lo studio degli antichi giacimenti delle fonti giudiziarie; la scoperta degli «uomini della memoria» e del funzionamento istituzionale delle cancellerie; infine il valore e il significato della memoria giudiziaria, soprattutto in riferimento alla costruzione dei nostri modelli e dei nostri riferimenti. Se questi assi tendono spesso nello studio a mescolarsi, tre prospettive si stagliano più chiaramente, modellando anche la struttura del volume: la scrittura degli atti della vita giudiziaria (da cui la prima parte, «Enregistrement: écrire et décrire»), la conservazione degli atti per la memoria - e di conseguenza le istituzioni e gli uomini che si dedicano a ciò - (da cui la seconda parte, "Conservation: hommes et institutions»); lo sfruttamento di questa memoria istituzionale per la redazione della storia e la formazione dunque di una nuova memoria, parallela o concorrente a essa (da cui l'ultima parte del libro, «Exploitation et mémoires concurrentes»).

5 I contributi (talvolta corredati di annessi ed indici), di cui non si può dar conto singolarmente, sono: Isabelle stoREZ-BRANCOURT, Introduction (pp. 5-11); nella Prima parte: Sophie DÉMARE-LAFONT, Écriture et archivage des procès en Mésopotamie (pp. 15-30), Olivier CANTEAUT, Les archives du Parlement au temps des Olim: considérations autour de fragments d'un rôle de 1287 (pp.31-66), Philippe PASCHEL, Le Manuel de Nicolas de Villemer (pp. 67-79), Sylvie DAUBRESSE, Le greffe du parlement de Paris à la fin du XVI eiècle: quel-ques opérations d'autocensure (pp. 81-91), Pascal BASTIEN, Le greffier en tant qu'exécuteur: parole rituelle et mort sans cadavre (Paris, XVII ${ }^{e}$-XVIII ${ }^{e}$ siècle) (pp. 93-102), Camille VIENNOT, Du casier judiciaire aux fichiers de police: la mise en mémoire des données en matière pénale (pp. 103-115); nella Seconda parte: Alexandre JEANNIN, Le greffier durant le haut Moyen Âge: quelle réalité? (pp.117-131), Monique MORGAT-BONNET, Brève histoire des origines médiévales du greffe du parlement de Paris (pp.133-149), Julie CLAUSTRE, Naissance d'une mémoire judiciaire: les débuts de la «clergie» du Châtelet de Paris (vers 1320-vers 1420) (pp. 151-161), Virginie LEMONNIER-LESAGE, La mémoire judiciaire à Metz à la fin du Moyen Âge: la conservation des jugements des maîtres-échevins (pp.163-180), Isabelle PAQUAY, Le prince, le maire, les échevins et les clercs, acteurs de la mémoire judiciaire et urbaine. Le cas de la Haute Cour de Namur au XV siècle (pp.181-206), François ZANATTA, Un acteur de la mémoire judiciaire urbaine: le conseiller pensionnaire dans les villes du Nord de la France ( $\mathrm{XIV}^{\mathrm{e}}$-XVIII ${ }^{\mathrm{e}}$ siècle) (pp. 207-216), Guillaume RATEL, Le labyrinthe des greffes du parlement de Toulouse, pivot de la pratique à l'époque moderne (1550-1778) (pp. 217-232), Camille DÉGEZ, La mémoire de la prison: les greffiers de la Conciergerie (Paris, fin $d u$ XVI e siècle-milieu $d u$ XVII siècle) (pp. 233-243), David FEUTRY, Sauver les archives, défendre le roi: la remise en ordre des registres du Parlement d'après les papiers du procureur général Joly de Fleury (pp. 245-252), Fabrice MAUCLAIR, Greffes et greffiers des justices seigneuriales au XVIII ${ }^{e}$ siècle (pp. 253-266); 
terza parte: Hélène MÉNARD, Ammien Marcellin: l'historien et la «mémoire judiciaire» à la fin $d u$ IV siècle après J.-C. (pp. 269-287), Laurent JÉGOU, «Qui perd gagne». La place de l'honneur dans la mémoire judiciaire aux IX $\mathrm{X}^{e} \mathrm{X}^{e}$ siècles (pp. 289-303), Patrick ARABEYRE, Mémoire judiciaire du parlement de Toulouse: le projet de Corpus parlamenteum d'Étienne Aufréri (fin du $X v^{e}$ siècle) (pp.305-318), Marie houllemare, Écrire la justice hors le greffe: la mémoire judiciaire dans la ville, à Paris, au XVI e siècle (pp. 319-333), Olivier CAPOROSSI, Naissance d'une mémoire judiciaire d'État: l'œuvre du juriste Francisco de Melgar et la junte royale du Bureau en 1695 (pp. 335-350), Louis DE CARBONNIÈRES, Les conséquences juridiques de l'erreur de plume devant le parlement de Paris sous Louis XV (pp.351-366), Émeline SEIGNOBOS, L'éloquence: histoire muette d'une autre mémoire judiciaire, des lendemains de la Seconde Guerre mondiale à nos jours (pp. 367-379), Françoise HILDESHEIMER, Conclusions (pp. 381-383). 